Dikirim: 20 Juli 2015 Diterbitkan: 1 Juli 2016

\title{
Determinan persalinan oleh tenaga kesehatan di Indonesia
}

\author{
Determinants of skilled birth attendants in Indonesia \\ Asep Hermawan ${ }^{1}$, Yayi Suryo Prabandari ${ }^{2}$, Siswanto Agus Wilopo ${ }^{3}$
}

\begin{abstract}
Purpose: This study aimed to find the relationship between health worker ratio with skilled birth attendants (SBA). Methods: This research was a cross-sectional study using data from Rifaskes 2011 (a nationwide survey of healthcare facilities), SP 2010 (population census), and Riskesdas 2013 (a nationwide survey based on community for basic health). The sample was total population of the district/city as many as 497 districts/cities. The unit of analysis of this study was the district/city in Indonesia. Statistical analysis used univariate analysis, bivariate analysis and generalized linear model (GLM). Results: There was no correlation between the ratio of health workers with SBA coverage. But, the GLM analyses showed positive correlation of midwives ratio in the population and SBA when regressed with physicians, nurses, accessibility to community health center (puskesmas) with OR 1.07 (95\% Cl: 1-1.14), status of region (remote, borderland or islands area) 1.07 (95\% Cl: 1.01-1.15), and administrative status (district/city) with OR 1.11 (95\% Cl: 1.03-1.19). Conclusion: The midwives ratio has a strong correlation with SBA after improving accessibility to primary health centers.
\end{abstract}

Keywords: SBA; health workers density; community health center

\footnotetext{
1 Puslitbang Sumberdaya dan Pelayanan Kesehatan, Badan Penelitian dan Pengembangan Kesehatan, Kementrian Kesehatan Jakarta (Email: kang.asep007@gmail.com)

${ }^{2}$ Departemen Perilaku Kesehatan, Lingkungan dan Kedokteran Sosial, Fakultas Kedokteran, Universitas Gadjah Mada

${ }^{3}$ Departemen Biostatistik, Epidemiologi dan Kesehatan Populasi, Fakultas Kedokteran, Universitas Gadjah Mada
} 


\section{PENDAHULUAN}

Indonesia merupakan satu dari 57 negara yang menghadapi krisis tenaga kesehatan dan 1 dari 5 negara di Asia Tenggara tengah menghadapi masalah maldistribusi tenaga kesehatan (1,2). Kekurangan tenaga didasarkan kepada densitas tenaga kesehatan (dokter, bidan, perawat) yang kurang dari batas treshold yang harus dipenuhi sebesar 23 per 10.000 penduduk untuk mencapai indikator kunci kesehatan masyarakat (3-5).

PBB mengestimasi ada 350.000 ibu melahirkan yang meninggal tiap tahun akibat kehamilan maupun persalinan di dunia, sedangkan di Asia Tenggara ada sekitar $18.000 \mathrm{ibu}$ yang meninggal akibat komplikasi kehamilan dan persalinan (6-7). Laos dan Kamboja merupakan 2 dari 7 negara di luar negara Sub-Sahara dengan angka kematian ibu tertinggi di dunia dan Indonesia adalah satu dari 11 negara yang berkontribusi terhadap 65\% kematian ibu di dunia (7). Di Indonesia, AKI cenderung fluktuatif. Pada tahun 2004 AKI di Indonesia adalah 307 per 100.000 kelahiran hidup pada 2007 menurun menjadi 228 per 100.000 kelahiran hidup (8). Target AKI pada 2014 adalah 118 per 100.000 kelahiran hidup (9).

Salah satu upaya efektif menurunkan angka kematian ibu adalah dengan meningkatkan pertolongan persalinan oleh tenaga kesehatan terlatih $(10,11)$. Secara nasional, persentase persalinan yang ditolong oleh tenaga kesehatan terlatih meningkat dari $66,7 \%$ pada tahun 2002 menjadi 77,34\% pada tahun 2009 (Susenas). Angka tersebut meningkat menjadi 82,3\% pada tahun 2010 (8), dan semakin meningkat pada 2013, angka persalinan oleh tenaga kesehatan mencapai 87,1\% (12).

Penelitian Robinson dan Wharrad menunjukkan bahwa densitas dokter memiliki efek menguntungkan pada kematian ibu, kematian bayi, dan balita. Penelitian Anand and Bärnighausen menunjukkan secara agregat sumber daya manusia kesehatan (dokter, perawat, dan bidan bersama-sama) berpengaruh signifikan terhadap penurunan angka kematian ibu, bayi, dan balita setelah dikontrol dengan variabel lain yang digunakan untuk menjelaskan ketiga hasil kesehatan tersebut (13).

Literatur lain menjelaskan bahwa akses terhadap pelayanan dipengaruhi oleh ketersediaan layanan kesehatan, atau jarak terhadap pengguna layanan (waktu tempuh, jarak tempuh, dan kondisi di pelayanan kesehatan, seperti jenis pelayanan, tenaga kesehatan yang tersedia dan jam buka), status sosial ekonomi masyarakat dan tingkat pendidikan, serta serta sikap dan pengetahuan tentang pelayanan kesehatan yang dibutuhkan (14-20). Oleh karena itu, perlu dilakukan analisis yang menilai hubungan antara rasio tenaga kesehatan strategis (dokter, bidan dan perawat) dengan cakupan persalinan oleh tenaga kesehatan di Indonesia karena belum dilakukan untuk skala nasional. Penelitian ini bertujuan mengidentifikasi hubungan antara rasio tenaga kesehatan dengan persalinan oleh tenaga kesehatan

\section{METODE}

Penelitian kuantitainf ini menggunakan desain cross sectional dengan unit analisis kabupaten/kota. Data yang digunakan berasal dari beberapa survei, yaitu Riset Fasilitas Kesehatan (Rifaskes) 2011, Riskesdas 2013 dan beberapa variabel yang diambil dari sensus penduduk serta laporan Badan Pusat Statistik (BPS). Variabel dependen adalah persentase persalinan oleh tenaga kesehatan tiap kabupaten/kota. Variabel independen adalah densitas tenaga kesehatan (dokter, perawat, dan bidan) per 10.000 penduduk (merupakan komposit dari jumlah tenaga dokter umum, bidan dan perawat), densitas dokter per 10.00 penduduk, densitas perawatan per 10.000 penduduk dan densitas bidan per 10.000 penduduk. Variabel confounding penelitian ini adalah tingkat pendidikan, pengetahuan, biaya, waktu tempuh, status sosial ekonomi, produk domestik regional bruto, daerah tertinggal perbatasan dan kepualauan (DTPK)/non DTPK, dan status administratif kabupaten/kota. Cara ukur variabel penelitian meliputi telaah dokumen, wawancara, dan observasi.

Analisis data menggunakan uji generalized linear model (family) binomial (link) logit dengan alpha 0,05\% atau confidency $95 \%$.

\section{HASIL}

Penelitian ini menemukan persalinan oleh tenaga kesehatan sebesar 81,6\%, rasio dokter/10.000 penduduk 1,812, rasio perawat/10.000 penduduk 13,081, rasio bidan/10.000 penduduk 13,081, rasio nakes/10.000 penduduk 22,294. Sedangkan rerata variabel proporsi wanita usia subur (WUS) dengan pendidikan SD ke atas 98,325, proporsi rumah tangga yang mengetahui keberadaan puskesmas terdekat 89,215, proporsi rumah tangga yang dengan biaya ke puskesmas $\leq 10.000$ 79,05, proporsi RT dengan jarak tempuh ke puskesmas $\leq 15$ menit 57,286, PDRB (10 t) 2,290, dan proporsi rumah tangga dengan kuintil indeks kepemilikan menengah ke atas 55,631 (Tabel 1). 
Tabel 1. Deskripsi statistik variabel dependen, independen utama dan confounding variable $(\mathrm{N}=497) 1 \mathrm{kolom}$

\begin{tabular}{|c|c|c|c|c|c|c|}
\hline Variabel & Mini mum & p 25* & p50** & p75*** & Maksimum & rerata \\
\hline Persalinan oleh tenaga kesehatan & 0,029 & 0,724 & 0,883 & 0,968 & 1,000 & 0,816 \\
\hline Rasio dokter per 10.000 penduduk & 0,241 & 0,934 & 1,491 & 2,271 & 13,970 & 1,812 \\
\hline Rasio perawat per 10.000 penduduk & 0,321 & 6,609 & 11,139 & 17,767 & 69,658 & 13,081 \\
\hline Rasio bidan per 10.000 penduduk & 0,505 & 4,167 & 6,105 & 9,093 & 27,223 & 7,402 \\
\hline Rasio nakes per 10.000 penduduk & 1,435 & 12,854 & 19,500 & 28,921 & 100,077 & 22,294 \\
\hline Rasio dokter per 10.000 penduduk tiap $10.000 \mathrm{Km}^{2}$ & 0,306 & 2,798 & 6,715 & 21,327 & 6254,982 & 79,212 \\
\hline Rasio perawat per 10.000 penduduk tiap $10.000 \mathrm{Km}^{2}$ & 2,546 & 21,823 & 50,320 & 130,706 & 27449,640 & 520,475 \\
\hline Rasio bidan per 10.000 penduduk tiap $10.000 \mathrm{Km}^{2}$ & 1,172 & 15,093 & 35,284 & 74,410 & 7595,336 & 187,106 \\
\hline Rasio tenaga Kesehatan per 10.000 penduduk Tiap $10.000 \mathrm{Km}^{2}$ & 5,092 & 42,546 & 94,686 & 234,966 & 39317,030 & 786,793 \\
\hline Proporsi WUS dengan pendidikan SD ke atas & 36,560 & 86,770 & 91,120 & 94,300 & 98,950 & 89,325 \\
\hline Proporsi RT yang Mengetahui keberadaan Puskesmas terdekat & 47,320 & 84,450 & 91,680 & 96,110 & 100,000 & 89,219 \\
\hline Proporsi RT yang dengan biaya ke Puskesmas $\leq 10.000$ & 21,350 & 70,770 & 81,920 & 90,110 & 99,830 & 79,051 \\
\hline Proporsi RT dengan jarak tempuh ke puskesmas $\leq 15$ Menit & 2,600 & 45,800 & 58,800 & 70,700 & 96,900 & 57,286 \\
\hline PDRB (10 t) & 0,255 & 0,950 & 1,373 & 2,041 & 41,494 & 2,290 \\
\hline Status sosial ekonomi & 0,000 & 37,100 & 57,590 & 75,840 & 98,900 & 55,631 \\
\hline
\end{tabular}
Sumber data: SP 2010, Rifaskes 2011, dan Riskesdas 2013; * p25: persentil 25;** p50: persentil 25;***p75: persentil 75

Hubungan rasio dokter, bidan, dan perawat/10.000 penduduk terhadap proporsi persalinan oleh tenaga kesehatan tidak menunjukkan hubungan bermakna secara statistik. Jika memperhatikan luas wilayah, hubungan rasio tenaga kesehatan baik dokter/10.000 penduduk tiap $10.000 \mathrm{~km} 2$, bidan/10.000 penduduk tiap $10.000 \mathrm{~km} 2$, perawat $/ 10.000$ penduduk tiap 10.000 km2 maupun total nakes/10.000 penduduk tiap 10.000 km2, memiliki signifikansi positif. Proporsi WUS dengan pendidikan SD ke atas, proporsi rumah tangga yang dengan biaya ke puskesmas $\leq \mathrm{Rp}$. 10.000, proporsi rumah tangga dengan jarak tempuh ke puskesmas $\leq 15$ menit, proporsi RT dengan kuintil indeks kepemilikan menengah ke atas, status DTPK dan status kabupaten/kota berhubungan dengan persalinan oleh nakes (Tabel 2).

Tabel 2. Hubungan antara variabel independen utama dan confounding variable dengan persalinan oleh tenaga kesehatan dengan menggunakan analisis generalized linear model (GLM)

\begin{tabular}{|c|c|c|}
\hline Variabel & OR & $95 \% \mathrm{CI}$ \\
\hline Rasio dokter per 10.000 penduduk & 0,945 & $0,808-1,105$ \\
\hline Rasio perawat per 10.000 penduduk & 0,992 & 0,967-1,017 \\
\hline Rasio bidan per 10.000 penduduk & 1,035 & 0,983-1,09 \\
\hline Rasio nakes per 10.000 penduduk & 1,000 & $0,982-1,018$ \\
\hline Rasio dokter per 10.000 penduduk tiap $10.000 \mathrm{Km}^{2}$ & 1,005 & $1-1,009$ \\
\hline Rasio perawat per 10.000 penduduk tiap $10.000 \mathrm{Km}^{2}$ & 1,001 & $1-1,001$ \\
\hline Rasio bidan per 10.000 penduduk tiap $10.000 \mathrm{Km}^{2}$ & 1,003 & $1,001-1,006$ \\
\hline Rasio tenaga kesehatan per 10.000 penduduk tiap $10.000 \mathrm{Km}^{2}$ & 1,001 & $1-1,001$ \\
\hline Proporsi WUS dengan pendidikan SD ke atas & 1,090 & $1,057-1,123$ \\
\hline Proporsi RT yang mengetahui keberadaan puskesmas terdekat & 1,009 & $0,985-1,033$ \\
\hline Proporsi RT yang dengan biaya ke puskesmas $\leq \mathrm{Rp} 10.000$ & 1,036 & $1,02-1,052$ \\
\hline Proporsi RT dengan jarak tempuh ke puskesmas $\leq 15$ menit & 1,035 & $1,023-1,048$ \\
\hline PDRB (10 T) & 1,104 & $0,974-1,25$ \\
\hline Proporsi RT dengan kuintil indeks kepemilikan menengah ke atas & 1,043 & $1,032-1,055$ \\
\hline Status DTPK & 3,809 & $2,359-6,151$ \\
\hline Kabupaten/Kota & 4,690 & $1,091-1,152$ \\
\hline
\end{tabular}
Sumber data: SP 2010, Rifaskes 2011, dan Riskesdas 2013; OR: odds ratio

Model hubungan antara rasio dokter/10.000 penduduk, rasio perawat/10.000 penduduk, dan rasio bidan/10.000 penduduk terhadap persalinan oleh tenaga kesehatan yang menunjukkan bahwa rasio bidan/10.000 penduduk memberikan dampak terhadap perbaikan persalinan oleh tenaga keseahatan, yaitu pada model III dengan OR 1,07 (95\% CI 1-1,14), model V dengan OR 1,07 (95\% CI 1,01-1,15) dan model VI dengan OR 1,11 ( 95\% CI 1,03-1,19). Namun, berdasarkan nilai log likelihood (LL) dan Akaike's information criterion
(AIC), model III (AIC 304,11 dan LL -146,05) dan model VI (AIC 310 dan LL -144,20) merupakan nilai dengan prediksi model paling fit yaitu nilai AIC dan LL mendekati angka 0 (21). Berdasarkan analisis ini hanya rasio bidan/10.000 penduduk yang berdampak terhadap perbaikan persalinan oleh tenaga kesehatan yaitu tiap penambahan 1 bidan /10.000 penduduk menaikan $7 \%$ persalinan oleh tenaga kesehatan dengan memperhatikan aksesibilitas ke puskesmas dan status DTPK, dan 11\% jika memperhatikan status Kota. 


\section{BAHASAN}

Pertolongan persalinan oleh tenaga kesehatan terlatih untuk melakukan manajemen komplikasi kehamilan adalah cara yang efektif untuk menurunkan angka kematian ibu. WHO mendefinisikan tenaga kesehatan terlatih sebagai tenaga kesehatan dengan keterampilan kebidanan (bidan, dokter dan perawat dengan pendidikan kebidanan tambahan) yang telah dilatih untuk menguasai keterampilan yang diperlukan untuk mengelola persalinan normal dan mendiagnosis, mengelola atau merujuk komplikasi kebidanan (22).

Penelitian ini menunjukkan bahwa rasio tenaga kesehatan per 10.000 penduduk bervariasi. Perawat memiliki rerata rasio paling banyak yaitu 13,08, rasio bidan rerata 7,402 dan yang paling sedikit adalah rerata rasio dokter 1,812 . Rasio tersebut masih lebih rendah dibandingkan dengan sasaran capaian tenaga kesehatan yaitu dokter umum 48 per 100.000 penduduk, perawat 158 per 100.000 penduduk, bidan 75 per 100.000 penduduk (23). Jika dihitung secara agregat tenaga kesehatan (dokter, bidan dan perawat), maka rerata rasio tenaga kesehatan/10.000 penduduk 22,29 dengan SD 12,74. Rerata rasio ini berada di batas bawah critical shortage seperti yang didefinisikan WHO $(3,4)$. Sebaran tenaga kesehatan fasilitas kesehatan pemerintah di Jawa dan Bali lebih sedikit dibandingkan dengan wilayah lain. Walaupun demikian persentase persalinan oleh tenaga kesehatan dikedua wilayah tersebut lebih baik dari region lain. Hal ini disebabkan karena kontribusi tenaga kesehatan di fasilitas kesehatan swasta terhadap utilitas tenaga kesehatan dalam pertolongan persalinan.

Jika analisis memperhatikan luas wilayah, menunjukkan hasil yang berbeda. Rerata rasio dokter adalah 79,212 dan SD 353,511. Rerata rasio perawat 520,475 dan SD 2181,119. Rerata rasio bidan dengan nilai 187,106 dan SD 619,225, sedangkan untuk agregat tenaga kesehatan rerata nya adalah 786,79 dan SD 3051,25. Jika melihat SD dari analisis masing-masing tenaga kesehatan ataupun agregat, terlihat variasi yang sangat besar antar kabupaten/kota. Dengan demikian, jika memperhatikan luas wilayah maka besar jumlah tenaga kesehatan di wilayah Jawa dan Bali lebih tinggi dibandingkan dengan wilayah lainnya.

Penelitian ini menunjukkan bahwa hubungan rasio masing-masing tenaga kesehatan/10.000 Penduduk dan variabel lainnya yang memberikan pengaruh terhadap persalinan oleh tenaga kesehatan. Secara multivariat rasio bidan/10.000 penduduk yang berdampak terhadap perbaikanpersalinan oleh tenaga kesehatan, yaitu tiap penambahan 1 bidan /10.000 penduduk menaikkan 7\% persalinan oleh tenaga kesehatan dengan memperhatikan aksesibilitas ke puskesmas dan status DTPK, dan 11\% jika memperhatikan status kota. Namun, berdasarkan nilai log likelihood (LL) dan Akaike's information criterion (AIC), model III) dan model VI merupakan nilai dengan prediksi model paling fit dan yaitu nilai AIC dan LL mendekati angka 0 (Tabel 3) (21).

Tingkat pendidikan pada penelitian ini diukur dengan proporsi WUS dengan pendidikan minimal SD. Hasil penelitian menunjukkan bahwa rerata proporsi WUS dengan pendidikan minimal SD di Indonesia adalah 89,33\%. Tingkat pendidikan memberikan gambaran pengetahuan tentang manfaat perawatan kesehatan preventif dan penggunanan pelayanan kesehatan, kemudahan untuk menerima informasi kesehatan, kemudahan tersosialisasi dengan layanan formal di luar lingkungan rumah. Sebagai contoh ibu yang buta huruf/dengan tingkat pendidkan rendah kurang bisa mengakses informasi komplikasi obstetri yang akan terjadi sehingga ibu kurang mampu mencari pertolongan untuk pencegahan komplikasi yang akan terjadi. Hal ini akan menyebabkan keterlambatan dalam menerima perawatan tenaga kesehatan terlatih walaupun fasilitas tersebut tersedia. Hasil penelitian ini memperkuat penelitian sebelumnya yang menunjukkan bahwa terdapat hubungan bermakna antara tingkat pendidikan dengan utilisasi tenaga kesehatan terlatih (15-18).

Akses pelayanan kesehatan yang berkualitas sangat penting untuk meningkatkan derajat kesehatan ibu. Beberapa hal yang bisa menghambat akses terhadap hal ini di antranya jarak yang jauh, harga layanan tidak terjangkau, fasilitas kurang bisa diakses karena beberapa alasan seperti jam kehadiran tenaga kesehatan yang tidak menentu, perilaku yang kurang ramah terhadap pelanggan, hambatan budaya, dan sebagainya (14). Secara bivariat penelitian menunjukkan bahwa proporsi RT yang mengetahui keberadaan puskesmas terdekat dengan persalinan oleh tenaga kesehatan tidak menunjukkan hubungan yang bermakna. Secara statistik pengaruh proporsi RT yang dengan biaya ke puskesmas $\leq$ Rp 10.000 terhadap persalinan oleh tenaga kesehatan menunjukkan hubungan yang bermakna. Variabel aksesibilitas lain yaitu proporsi RT dengan jarak tempuh ke puskesmas $\leq 15$ menit, secara statisitik menunjukkan hubungan bermakna. Dengan demikian, jika berdasarkan ketiga parameter tersebut maka biaya dan jarak tempuh memiliki hubungan yang bermakna dengan utilisasi tenaga kesehatan sebagai penolong persalinan di Indonesia. 
Program intervensi kesehatan kadang-kadang hanya berorientasi pada supply side dan mengabaikan faktor-faktor sosial yang menghambat akses dan penggunaan pelayanan kesehatan efektif. Padahal, hasil penelitian secara konsisten menunjukkan bahwa status sosial keluarga berhubungan dengan perilaku ibu/keluarga dalam pencarian pelayanan kesehatan. Beberapa penelitian menunjukkan bahwa ibu kelompok pendapatan tinggi memiliki peluang lebih tinggi untuk memanfaatkan tenaga kesehatan terlatih pada saat melahirkan dibandingkan dengan ibu dari kelompok pendapatan rendah (15,17-18). Hasil penelitian ini memperkuat penelitian sebelumnya, yaitu nilai rerata proporsi rumah tangga dengan sosial ekonomi baik seperti wilayah Aceh, sebagiain besar Sulawesi Sumatera Utara, Jawa dan Bali, Kalimantan dan Sulawesi memiliki cakupan persalinan oleh tenaga kesehatan yang lebih baik. Secara bivariat status sosial ekonomi memiliki hubungan yang bermakna terhadap persalinan oleh tenaga kesehatan. Hal ini didukung oleh uji korelasi dengan scatterplot yang menunjukkan bahwa semakin proporsi kabupaten dengan status sosial ekonomi tinggi semakin tinggi proporsi persalinan oleh tenaga kesehatan.

Penelitian ini menunjukkan bahwa walaupun PDRB tidak memiliki hubungan yang bermakna (95\% CI 0,974-1,25), namun memiliki OR lebih baik dibandingkan dengan variabel lainya (OR 1,104) terhadap cakupan persalinan oleh tenaga kesehatan. Walupun demikian beberapa penelitian menunjukkan bahwa negara yang memiliki pendapatan per kapita tinggi memiliki kualitas hidup yang lebih baik dibandingkan dengan negara yang memiliki pendapatan per kapita yang rendah. Negara dengan gross national product (GNP) tinggi berkorelasi signifikan dengan utilisasi tenaga kesehatan untuk menolong persalinan $(17,24,25)$.

Penelitian ini menunjukkan bahwa status DTPK dengan 95\% CI 2,359-6,151 dan OR 3,809, yaitu daerah non-DTPK memiliki peluang untuk persalinan ditolong tenaga kesehatan lebih baik sebesar 3,089 kali dibandingkan dengan kawasan DTPK. Dengan demikian, kabupaten yang berada di daerah tertinggal, perbatasan dan kepulauan memiliki potensi cakupan persalinan oleh tenaga kesehatan lebih rendah dari kabupaten/kota dengan kondisi sebaliknya. Beberapa kendala yang dihadapi masyarakat yang tinggal di daerah DTPK di antaranya adalah kendala geografis dan sosial (tingkat kemiskinan masyarakat masih tinggi), keterbatasan sarana prasarana layanan kesehatan, dan minat rendah tenaga kesehatan yang bersedia ditempatkan di wilayah DTPK turut me- nyumbang rendah indikator status kesehatan masyarakat (26).

Status adminstrasi kota 4,69 kali berpeluang untuk memiliki proporsi persalinan oleh tenaga kesehatan lebih tinggi dibandingkan dengan kabupaten. Beberapa penelitian menunjukkan bahwa ibu yang tinggal di wilayah urban berpeluang untuk melahirkan di fasilitas pelayanan kesehatan lebih tinggi dibanding rural (15-16). Hal ini disebabkan karena secara umum daerah perkotaan memiliki penduduk dengan tingkat pendidikan lebih baik, status sosial ekonomi, rata-rata PDRB dan kesehatan yang lebih baik dibandingkan dengan kabupaten. Demikian pula daerah perkotaan memiliki fasilitas pendidikan, fasilitas pelayanan publik (termasuk tranfortasi publik), fasliltas kesehatan dan tenaga profesional kesehatan lebih baik dibandingkan dengan kabupaten. Hal ini berpengaruh terhadap akses layanan kesehatan secara keseluruhan, termasuk utilitas pelayanan tenaga kesehatan penolong persalinan. Hal lain adalah ibu di perkotaan lebih mudah mendapatkan informasi tentang komplikasi keahamilan dan persalinan dibanding dengan ibu di daerah rural.

\section{SIMPULAN}

Maldistribusi tenaga kesehatan masih menjadi masalah di Indonesia. Kabupaten/kota dengan jumlah tenaga kesehatan terbanyak berada di Jawa, Bali, dan Sumatera. Sebaliknya, di kawasan timur Indonesia jumlah tenaga kesehatan jauh lebih sedikit. Disparitas juga terjadi antara wilayah urban dan rural, yaitu jumlah tenaga di wilayah urban area lebih tinggi dibandingkan dengan rural area. Wilayah perbatasan, kepulauan dan beberapa daerah jumlah tenaga kesehatan sangat terbatas.

Rasio bidan per 10.000 penduduk berpengaruh terhadap persalinan oleh tenaga kesehatan setelah dimodifikasi oleh aksesibilitas terhadap puskesmas dan status non DTPK serta status administrasi kota. Penelitian ini mempertegas bahwa penolong persalinan yang paling banyak di Indonesia bukan dokter atau perawat, tetapi bidan, jika akses tersedia dengan baik.

Penempatan tenaga kesehatan untuk meningkatkan cakupan persalinan oleh tenaga kesehatan sebaiknya diikuti oleh perbaikan disektor lain. Karena secara statistik, status sosial ekonomi, tingkat pendidikan WUS, aksesibilitas terhadap fasilitas layanan kesehatan, dan PDRB berhubungan secara signifikan dengan utilisasi tenaga kesehatan sebagai penolong persalinan. 


\section{Abstrak}

Tujuan: Penelitian ini bertujuan mengidentifikasi hubungan antara rasio tenaga kesehatan dengan persalinan oleh tenaga kesehatan setelah dikontrol oleh confounding variable, yaitu pendidikan ibu, status sosial ekonomi, aksesabilitas terhadap puskesmas, status DTPK/non-DTPK, status kabupaten/kota dan PDRB. Metode: Penelitian merupakan penelitian non ekperimnental dengan pendekatan cross sectional. Sumber data menggunakan data Rifaskes 2011, SP 2010, dan data Riskesdas 2013 dan data BPS lainnya. Populasi penelitian ini adalah semua kabupaten/kota di Indonesia pada 2013. Sampel adalah total populasi kabupaten/kota, yaitu sebanyak 497 kabupaten/kota. Analisis yang digunakan adalah analisis univariabel, bivariabel dan multivariabel. Hasil: Secara statistik, rasio tenaga kesehatan baik secara agregat maupun terpisah, tidak berhubungan secara signifikan dengan persalinan oleh tenaga kesehatan. Analisis multivariabel dengan uji generalized linear model (GLM) menunjukkan hubungan bermakna antara rasio bidan/10.000 penduduk dengan persalinan oleh tenaga keseahtan ketika diregresikan dengan dokter, perawat, aksesibilitas ke puskesmas dengan OR 1,07 (95\% CI 1-1,14), status DTPK dengan OR 1,07 (95\% CI 1,01-1,15), dan status administratif (kabupaten/kota) dengan OR 1,11 ( 95\% CI 1,03-1,19. Simpulan: Tenaga kesehatan yang berpengaruh terhadap persalinan oleh tenaga kesehatan adalah rasio bidan/10.000 penduduk dengan memperbaiki akses ke fasilitas layanan kesehatan (puskesmas).

Kata kunci: persalinan oleh tenaga kesehatan, rasio tenaga kesehatan, puskesmas

\section{PUSTAKA}

1. World Health Organization. The world health report: 2006: working together for health. 2006.

2. Kanchanachitra C, et al. Human resources for health in southeast Asia: shortages, distributional challenges, and international trade in health services. The Lancet. 2011;377(9767):769-81.

3. Joint Learning Initiative. Human resources for health: overcoming the crisis. Global Equity Initiative. 2004.

4. Chen L, et al. Human resources for health: overcoming the crisis. The Lancet. 2004;364(9449):1984-90.

5. Dreesch N, et al. An approach to estimating human resource requirements to achieve the Millennium Development Goals. Health Policy and Planning. 2005;20(5):267-76.

6. World Health Organization. Trends in maternal mortality: 1990 to 2008. Geneva: WHO. 2010.

7. Acuin CS, et al. Maternal, neonatal, and child health in southeast Asia: towards greater regional collaboration. The Lancet. 2011;377(9764):516-25.
8. Hernawati I. Analisis Kematian Ibu Di Indonesia Tahun 2010 Berdasarkan Data SDKI, Riskesdas dan laporan rutin KIA. Online) diunduh; 2011.

9. Kementrian Perencanaan Pembangunan Nasional. Peraturan Presiden Republik Indonesia Nomor 5 Tahun 2010 Tentang Rencana Pembangunan Jangka Menengah Nasional (RPJM) Tahun 2010-2014. Diunduh; 2010.

10. WHO ICM \& FIGO. Making Pregnancy Safer: The Critical Role of The Skilled Attendant: A Joint Statement by WHO, ICM and FIGO. Geneva: WHO. 2004.

11. World Health Organization. Making Preganancy Safer: Skilled Birth Attendants. Geneva; 2008.

12. Badan Penelitian dan Pengembangan Kesehatan. Riset kesehatan dasar 2013. Jakarta: Kementrian Kesehatan Republik Indonesia. 2013.

13. Anand S, Bärnighausen T. Human resources and health outcomes: cross-country econometric study. The Lancet. 2004;364(9445):1603-9.

14. Frenk J \& White KL. The concept and measurement of accessibility. PAHO Scientific Publication: Pan American Health Organization; 1992. p. 842-55.

15. Kabakyenga JK, et al.. Influence of birth preparedness, decision-making on location of birth and assistance by skilled birth attendants among women in south-western Uganda. PloS one. 2012;7(4):e35747.

16. Teferra AS, Alemu FM, \& Woldeyohannes SM. Institutional delivery service utilization and associated factors among mothers who gave birth in the last 12 months in Sekela District, North West of Ethiopia: A community-based cross sectional study. BMC pregnancy and childbirth. 2012;12(1):1.

17. Kruk ME, Prescott MR, \& Galea S. Equity of skilled birth attendant utilization in developing countries: financing and policy determinants. American Journal of Public Health. 2008;98(1):142-7.

18. Ahmed S, Creanga AA, Gillespie DG, \& Tsui AO. Economic status, education and empowerment: implications for maternal health service utilization in developing countries. PloS one. 2010;5(6):e11190.

19. Sinay T. Access to quality health services: determinants of access. Journal of health care finance. 2001;28(4):58-68.

20. Kim K, \& Moody PM. More resources better health? A cross-national perspective. Social science \& medicine. 1992;34(8):837-42.

21. Burnham KP, \& Anderson DR. Multimodel inference understanding AIC and BIC in model selection. Sociological methods \& research. 2004;33(2):261-304.

22. WHO. Global action for skilled attendants for pregnant women: making pregnancy safer. 2002.

23. Badan Pengembangan dan Pemberdayaan Sumberdaya Manusia Kesehatan. Rencana pengembangan tenaga kesehatan 20112025. Jakarta: Kementerian Kesehatan; 2011.

24. Yanagisawa S, Oum S, \& Wakai S. Determinants of skilled birth attendance in rural Cambodia. Tropical Medicine \& International Health. 2006;11(2):238-51.

25. Buor D \& Bream K. An analysis of the determinants of maternal mortality in sub-Saharan Africa. Journal of Women's Health. 2004;13(8):926-38.

26. Lestari TRP. Pelayanan Kesehatan di Daerah Tertinggal, Perbatasan, dan Kepulauan. Info Singkat kesejahtraan sosial. 2013;Vol. V, No. 12/II/P3DI/Juni/2013:9-12. 